\title{
Twelve-year delay of a nipple-sharing graft: A case report
}

\author{
Tatiana KS Cypel MD MSc ${ }^{1}$, Mitchell Brown MD MEd FRCSC ${ }^{1,2}$
}

TKS Cypel, M Brown. Twelve-year delay of a nipplesharing graft: A case report. Can J Plast Surg 2013;21(3):190-191.

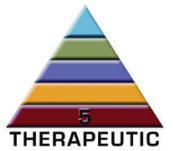

The present report describes the use of a nipple-sharing technique for nipple areolar reconstruction using a donor nipple that was initially grafted from the contralateral and healthy breast 12 years earlier. There are many different techniques available to reconstruct the nipple. Although nipple sharing is not feasible to use in all patients, when available, it is an ideal approach for matching the contralateral nipple in terms of shape, colour, texture and long-term projection.

\section{Une greffe de partage du mamelon 12 ans plus tard : rapport de cas}

Le présent rapport décrit le recours à une technique de partage du mamelon pour reconstruire un mamelon et une aréole,à partir du mamelon sain du sein opposé qui avait été greffé 12 ans auparavant. Il existe de nombreuses techniques de reconstruction du mamelon. Le partage du mamelon n'est pas toujours possible, mais lorsqu'il l'est, c'est la méthode idéale pour le faire correspondre au mamelon opposé, tant sur le plan de la forme, de la couleur et de la texture que de la projection à long terme.

Key Words: Nipple areolar complex reconstruction; Nipple sharing

Surgical treatment of breast cancer has evolved from radical mastec$\checkmark$ tomy with removal of the nipple areolar complex (NAC), to breast conservation therapy with preservation of the breast and NAC. Increasing interest in improved cosmesis has led to the introduction of the skin-sparing and nipple-sparing mastectomy as potential alternatives to complete mastectomy (1). There continue to be clinical situations in which the NAC is removed to either treat disease or as a component of breast cancer risk reduction. Several techniques are available to reconstruct the NAC. Achievement of consistent quality results remains a challenge. Often, multiple surgical procedures are required to achieve an acceptable cosmetic outcome. Jabor et al (2) reported a high level of dissatisfaction with NAC reconstructions, with only $16 \%$ of patients stating they had no desire to change their reconstruction. The remaining patients reported, in decreasing order, dissatisfaction with the nipple projection, colour match, shape, size, texture and position of their reconstructed NAC. Holding to the principle of reconstructing like tissue with like tissue, the nipple-sharing composite graft is an ideal approach for unilateral reconstruction. Requirements for this technique include unilateral reconstruction, a donor nipple of adequate size and patient consent for partial removal of the remaining normal nipple.

\section{CASE PRESENTATION}

A 42-year-old woman presented with a right breast invasive carcinoma in 1998 for which she underwent modified radical mastectomy. Delayed reconstruction was performed by the senior author in 1999 using a free transverse rectus abdominus myocutaneous procedure. Later in the same year, the right NAC was reconstructed using the nipple-sharing technique and tattooing for the areola. The left nipple was used as the donor. The technique consisted of marking $50 \%$ of the existing nipple for harvesting while the nipple is in the erect state. The graft was harvested as a $90^{\circ}$ wedge with a No. 15 blade and primary closure was performed with interrupted 5-0 chromic sutures. It left an imperceptible scar at the mid portion of the nipple with a natural shape. The harvested graft was then placed on a de-epithelialized bed marked preoperatively in the standing position. The bed was designed based on the contralateral nipple base and the anticipated graft size. The de-epitheliazed base was created by elevating a bucket handle flap, allowing for revascularization from two surfaces (Figure 1). interrupted fashion.

In March 2009, the patient was diagnosed with ductal carcinoma in situ in the left breast. She underwent a simple mastectomy with needed. In December of the same year, the patient underwent a delayed reconstruction of the left breast with a tissue expander, which was eventually inflated to $520 \mathrm{~mL}$. In August 2011, the tissue expander was exchanged to a shaped, form-stable $550 \mathrm{~g}$ implant. In September 2012, the patient underwent left NAC reconstruction. Due to the minimal subcutaneous tissue over the implant reconstruction, local flaps for nipple reconstruction were not optimal. The previous right nipple graft had maintained excellent size and projection. It was decided to 'reshare' the right nipple back to its original left side, 12 years after initial grafting. Areola reconstruction was performed with simultaneous tattooing of a similar pigment shade to the initial reconstruction (Figure 2).

\section{DISCUSSION}

Breast reconstruction following mastectomy has become a standard component of treatment for patients requiring breast removal. Creation of a NAC is the final and important part of the breast reconstruction process. Various techniques using a variety of grafts or local flaps are available. In cases of bilateral nipple reconstruction, the same technique performed on each side will usually produce acceptable symmetry.

Unilateral reconstruction is the greatest challenge in nipple reconstruction because all aspects of the nipple, including size, shape, colour and texture, must be matched to successfully recreate the natural contralateral nipple. Most nipple reconstructive techniques fail to accomplish all of these goals. The most common failure of those techniques is loss of projection over time (3). The use of local flaps frequently fails to maintain projection; however, composite nipple sharing offers an alternative with a greater likelihood of long-term projection (4). Nipple sharing for nipple reconstruction is not new and was one of the first techniques reported in the literature (5). The technique is simple to perform and has changed little since its inception. However, there is a reluctance on the part of plastic surgeons to use the contralateral nipple as a donor site. Possible morbidity includes pain, numbness,
Absorbable 5-0 sutures were used to secure the graft to the bed in an negative sentinel node biopsy. Chemotherapy or radiation was not

${ }^{1}$ Women's College Hospital; ${ }^{2}$ Division of Plastic and Reconstructive Surgery, University of Toronto, Toronto, Ontario

Correspondence: Dr Mitchell H Brown, Division of Plastic and Reconstructive Surgery, Department of Surgery, University of Toronto,

790 Bay Street, Suite 410, Toronto, Ontario M5G 1N8. Telephone 416-323-6336, fax 416-323-6325,

e-maildrbrown@torontoplasticsurgery.com 


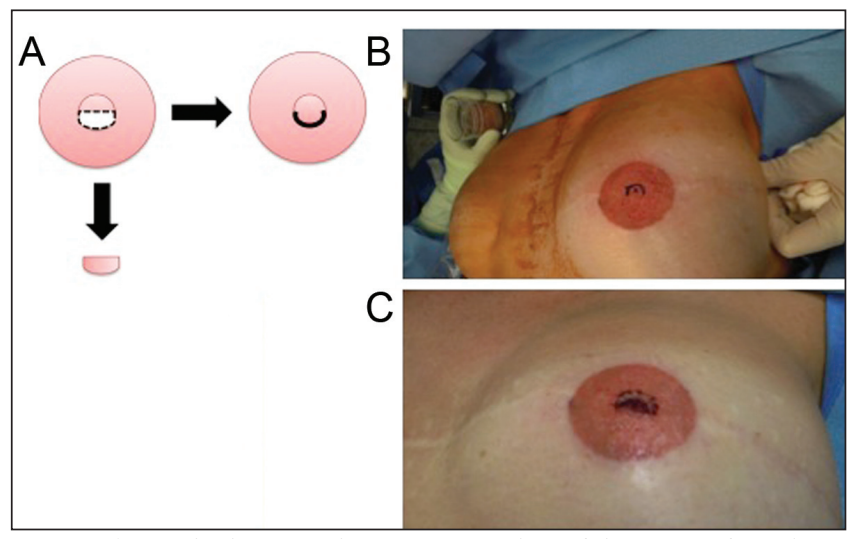

Figure 1) Nipple sharing technique. A Nipple graft harvesting from donor breast. B Bucket handle flap. C Nipple graft sutured in place in the recipient breast

disfigurement of the noncancerous breast, scarring, oncological fears, interference with future breastfeeding and anxiety from 'unnecessary' surgery on the normal breast. Moreover, nipple grafting may not be an option for all patients due to inadequate donor tissue. When available, the nipple-sharing composite graft provides a reconstructed nipple that will match the contralateral nipple as closely as possible in terms of shape, colour, texture and long-term projection (6).

Nipple sharing is subject to the risk of graft failure, but no more so than other graft options nor, probably, than the incidence of complications with flap techniques. Even with a degree of graft failure, symmetry may still be improved with sharing because of the reduction of the opposite nipple. Although nipple sharing has been described in the literature since the early 1970s, there is little or no discussion involving the patient's risk of developing cancer in the reconstructed breast as a consequence of tissue transplanted from a clinically benign breast. Basu et al (7) documented the first case in the literature of Paget disease of a reconstructed breast that was believed to be secondary to the nipple-sharing technique. The Paget disease in the left reconstructed breast likely originated from the donor right nipple, which was diagnosed with Paget disease many years after the nipplesharing procedure. It demonstrates that Paget disease of the nipple can be transplanted surgically from one breast to another. The paucity of such cases in the literature suggests that the occurrence of this clinical scenario is exceedingly rare but the risk certainly exists (7).

It is recommended that plastic surgeons inquire about family history and explore risk factors for possible bilateral breast cancer before using the contralateral nipple as a donor site. Preoperative assessment of the contralateral breast remains the accepted standard of care. Unfortunately, there is no method to prognosticate clinically undetectable disease in the donor breast. Although this phenomenon is a rare occurrence, the surgeon must be aware of the possibility of transferring an undetected premalignant or malignant lesion from the donor breast to the reconstructed breast.

Nipple sharing for nipple reconstruction in the unilateral breast cancer patient is a safe, reliable technique that offers the best possible

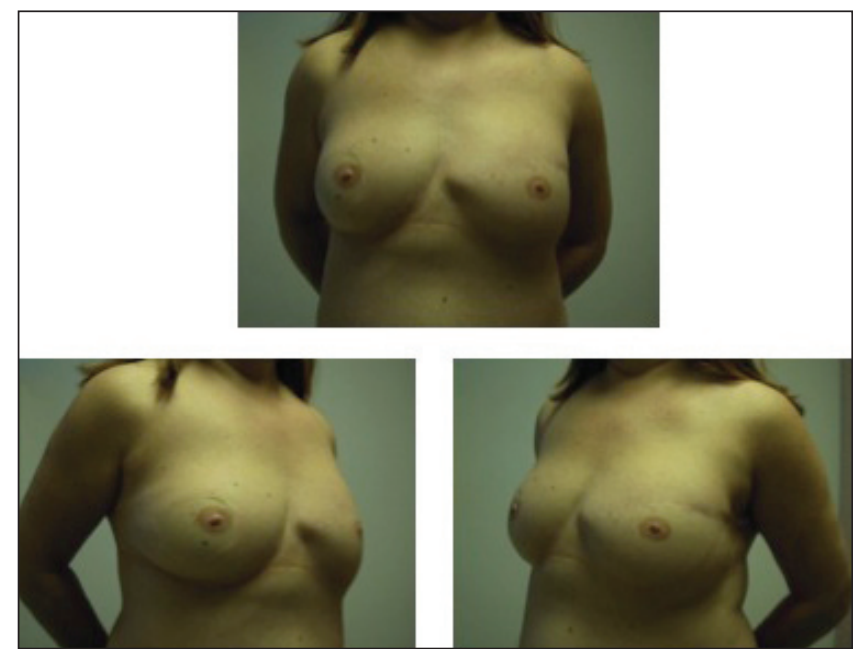

Figure 2) Right free transverse rectus abdominus myocutaneous reconstruction and left implant reconstruction. Three views taken six months following left nipple-areola reconstruction with tattoo and 'resharing' of the nipple graft placed 12 years earlier

match for the contralateral natural nipple. For issues of size, shape, colour and texture match, and for longevity of reconstruction, nipple sharing represents a solid option similar or superior to other flap techniques. In cases of previous mound irradiation or thin overlying tissues, nipple sharing may represent the only viable option for nipple reconstruction. The present report demonstrates the feasibility of this technique and the longevity of the results allowing for 'resharing' of the same graft 12 years later.

DISCLOSURES: Dr Cypel has no financial disclosures or conflicts of interest to declare. Dr Mitchell Brown is a consultant with Allergan Inc and a speaker for LifeCell Corporation.

\section{REFERENCES}

1. Chung AP, Sacchini V. Nipple-sparing mastectomy:

Where are we now? Surg Oncol 2008;17:261-6.

2. Jabor MA, Shayani P, Collins Jr DR, Karas T, Cohen BE.

Nipple areola reconstruction: Satisfaction and clinical

determinants. Plast Reconstr Surg 2002;110:457-63.

3. Richter DF, Reichenberger MA, Faymonville C. Comparison of nipple projection after reconstruction with three different methods. Handchir, Mikrochir, Plast Chir 2004;36:374-8.

4. Edsander-Nord A, Wickman M, Hansson P. Threshold of tactile perception after nipple-sharing: A prospective study. Scand J Plast Reconstr Surg Hand Surg 2002;36:216-20.

5. Gruber RP. Nipple-areola reconstruction: A review of techniques. Clin Plast Surg 1979;6:71-83.

6. Wraight WM, Davison JA. Nipple sharing for nipple-areolar complex reconstruction: Still a useful technique. J Plast Reconstr Aesthet Surg 2006;59:1471-2.

7. Basu CB, Wahba M, Bullocks JM, Elledge R. Paget disease of a nipple graft following completion of a breast reconstruction with a nipple-sharing technique. Ann Plast Surg 2008;60:144-5. 